\title{
Bildende Kunst als Ausdrucksmittel
}
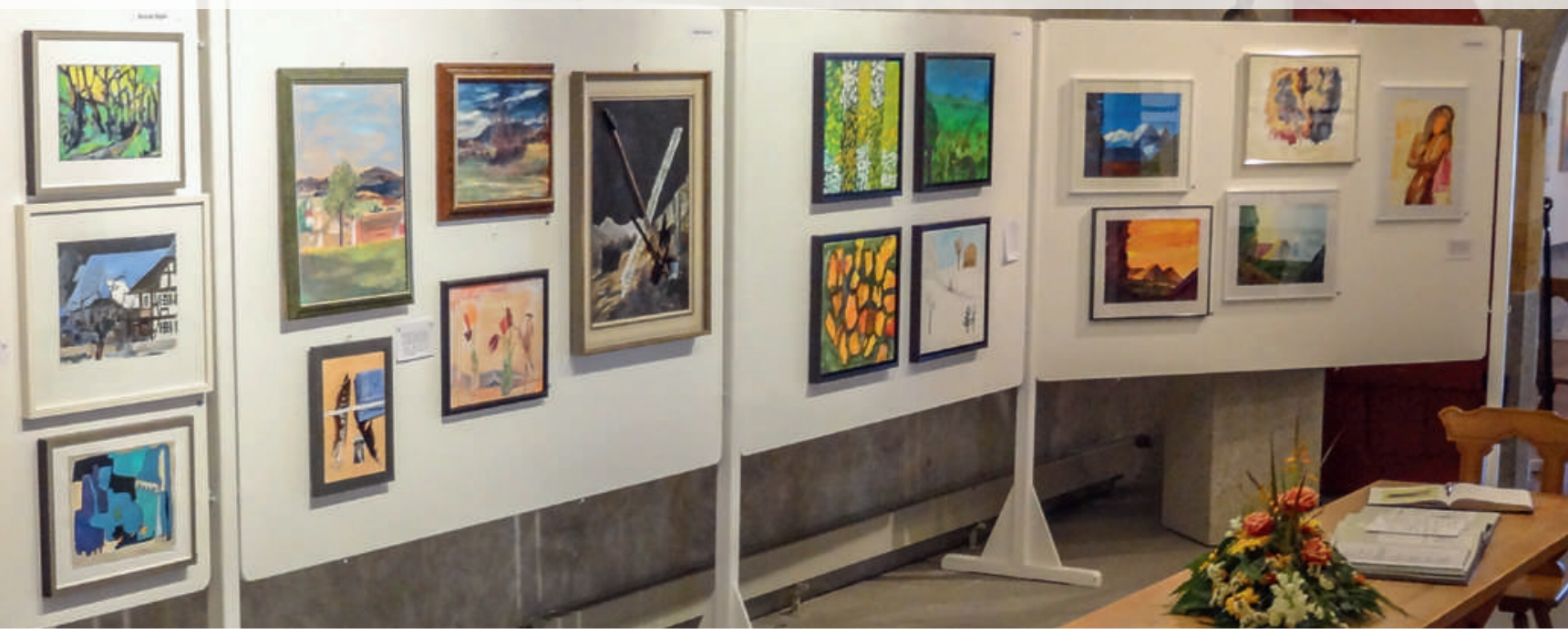

Harriet Keller-Wossidlo

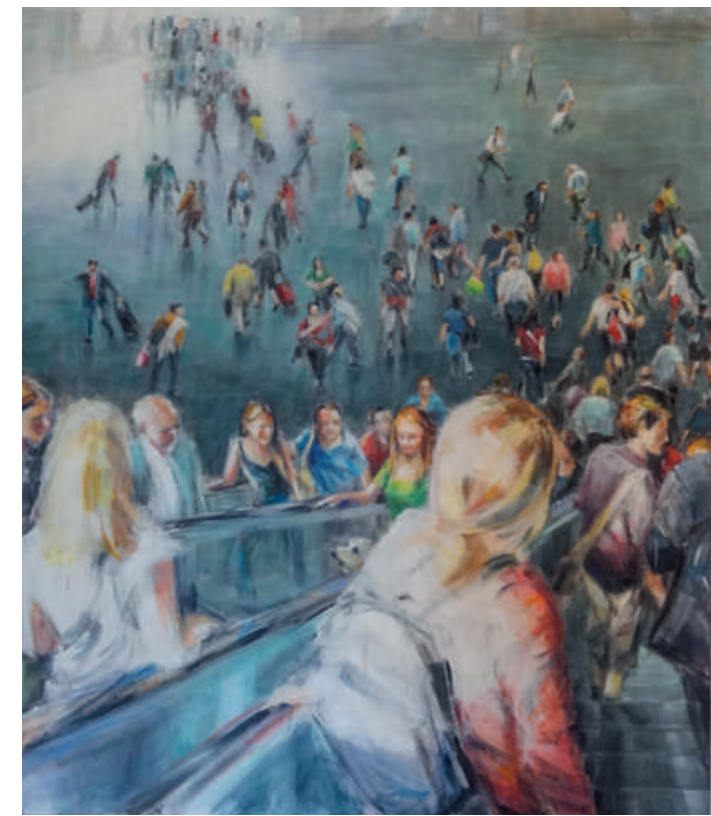

* Es ist immer auch die weibliche Form gemeint.

Korrespondenz:

Dr. med. Harriet Keller-Wossidlo Erlinsbacherstrasse 104 CH-5000 Aarau

harriet.keller[at]hotmail.ch

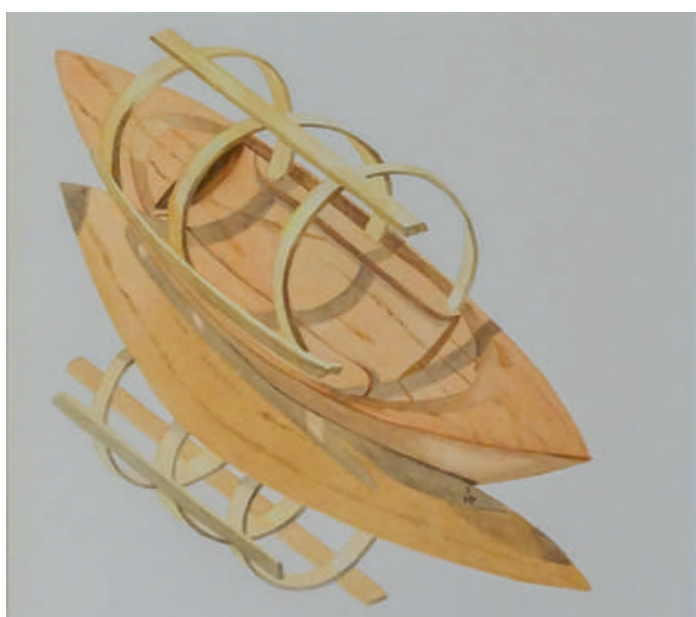

Mal wieder! An einem Sommertag in Murten, der See glitzerte im Sonnenschein, fand im Rathauskeller von Murten die traditionelle Vernissage der Kunstausstellung statt. Sie war sehr gut besucht von einem interessierten und auch fragenden Publikum. Die einführenden Worte sprach Herr A. Bruni, Journalist beim Murtenbieter. Es ergaben sich viele Gespräche mit interessierten Betrachtern*, nicht nur über die verwendeten Techniken und Materialien, sondern auch über Inhalte und Aussagen der Exponate. Die Künstler erlebten, wie ihre Werke durch das Betrachten ihre «Daseinsberechtigung» erhielten. Kunstwerke erfahren ihre Realität erst durch die Betrachtung.

Betrachtet werden konnten die verschiedensten Bildthemen, die zusammen mit Skulpturen und Tonarbeiten auch durch eine Vielfalt von verwendeten Materialien beeindruckten. Das Spektrum der ausgestellten Kunstwerke war exemplarisch für die Erlebensvielfalt des ärztlichen Berufs.

Es ist nicht so, dass Ärzte nur als Hobby und zum Ausgleich die bildende Kunst als Ausdrucksmittel wählen, sondern auch, weil Erfahrungen und Reflexionen durch das Erlebte verarbeitet und so zum Ausdruck kommen sollen. Entsprechend wählten einige Natur-, Blumen- und Sonnenthemen, die anderen verschlüsselte Hinweise auf Menschen und Situationen.

In zwei Sälen des Rathausgewölbes haben 27 berufstätige und ehemals berufstätige Künstler aus allen medizinischen Fachbereichen ihre Ausdrucksstrategien und auch ihr professionelles handwerkliches Können vorgestellt. Ungefähr 600 Besucher konnte diese sehr erfolgreiche Ausstellung verzeichnen, so

Oben: Katia Dormann, «Fahrt IV», Acryl auf Leinwand, 2014. Unten: Ulrich Siegfried, «Spiegelung», Aquarell, 2014. 


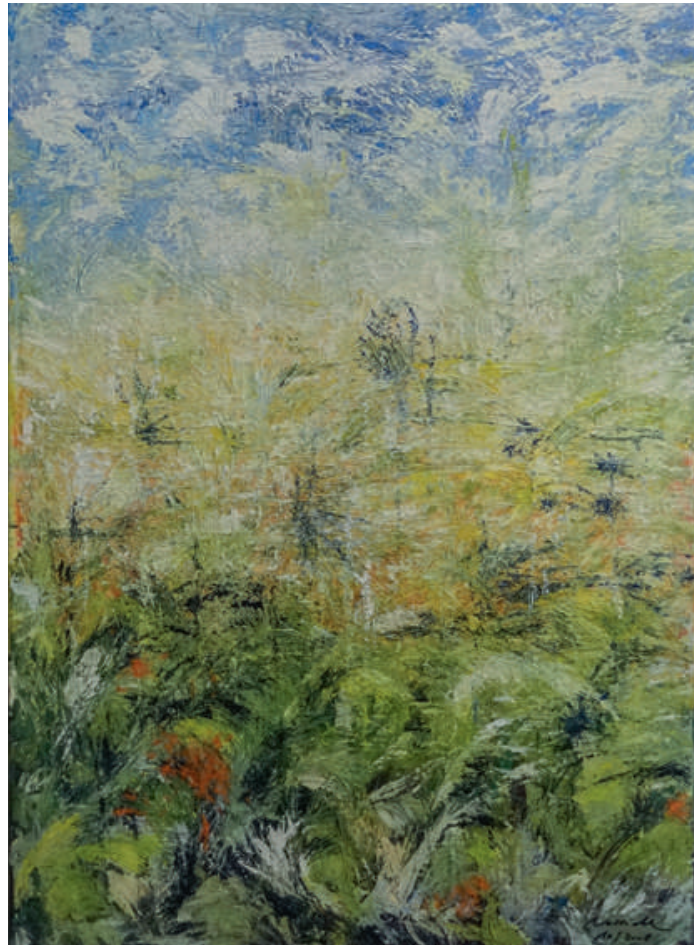

Harriet Keller-Wossidlo, «Wiese im Spätsommer», Acryl auf Leinwand gespachtelt.

dass abschliessend gesagt werden kann: Das, was uns im Medizinalbereich Tätige zur bildenden Kunst antreibt, wird verstanden und auch bewundert.

Der Ausdruck «ärztliche Heilkunst» beinhaltet ja bereits die Fähigkeit zur künstlerischen Tätigkeit: Denn es ist eine Kunst, für Patienten einzustehen, sich ihrer anzunehmen und gemeinsame Entscheidungen zu treffen: Diese Kunst setzt Kräfte frei, die weit über fachliches Wissen und Standards hinausgehen ... wir freuen uns auf Ihr Mitwirken.

Weitere Informationen über die Kunstausstellung der Schweizer Ärzte/Salon des Medécins Suisses finden Sie unter www.aerzte-kunst.ch

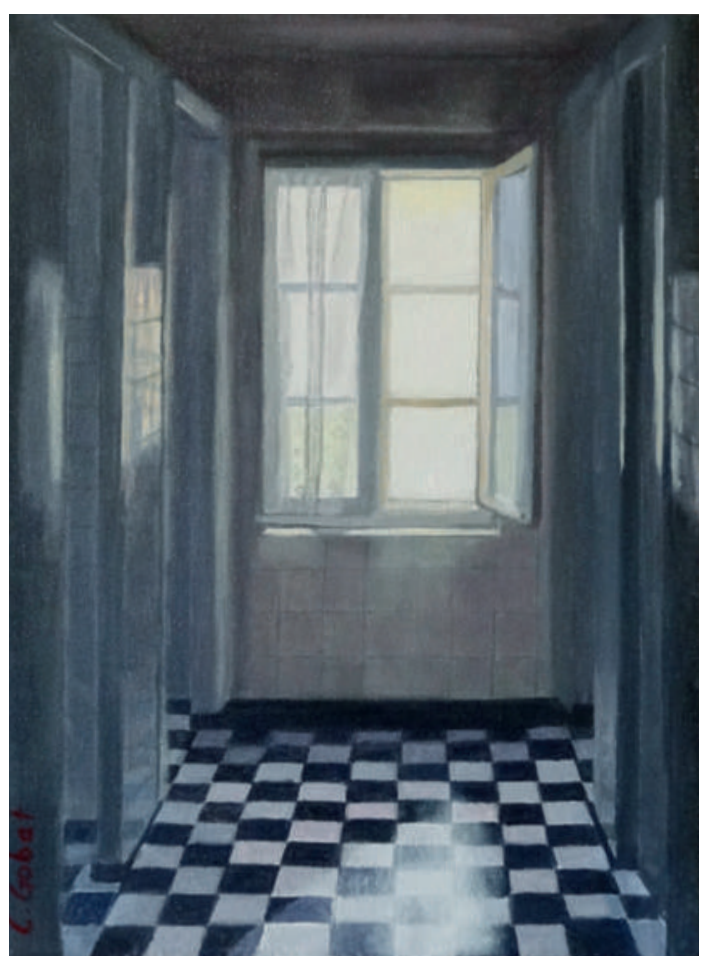

Catherine Gobat, «Lieux communs», huile sur toile.

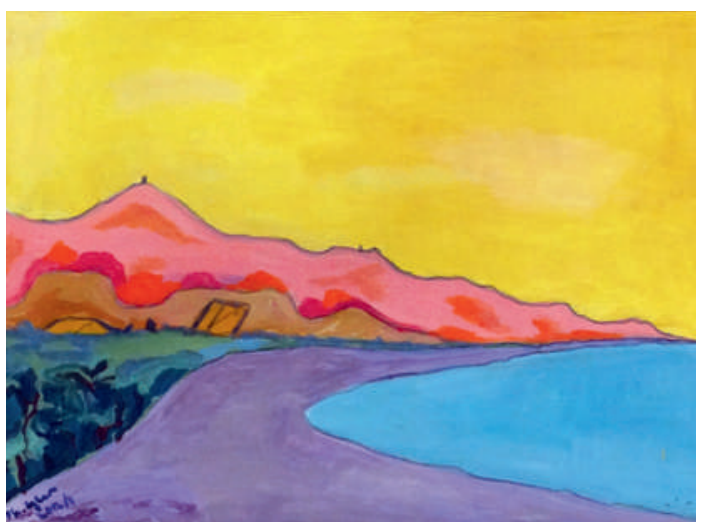

Oben: Philippe Lyrer, Landschaft auf einer Mittelmeerinsel I, Öl auf Leinwand.
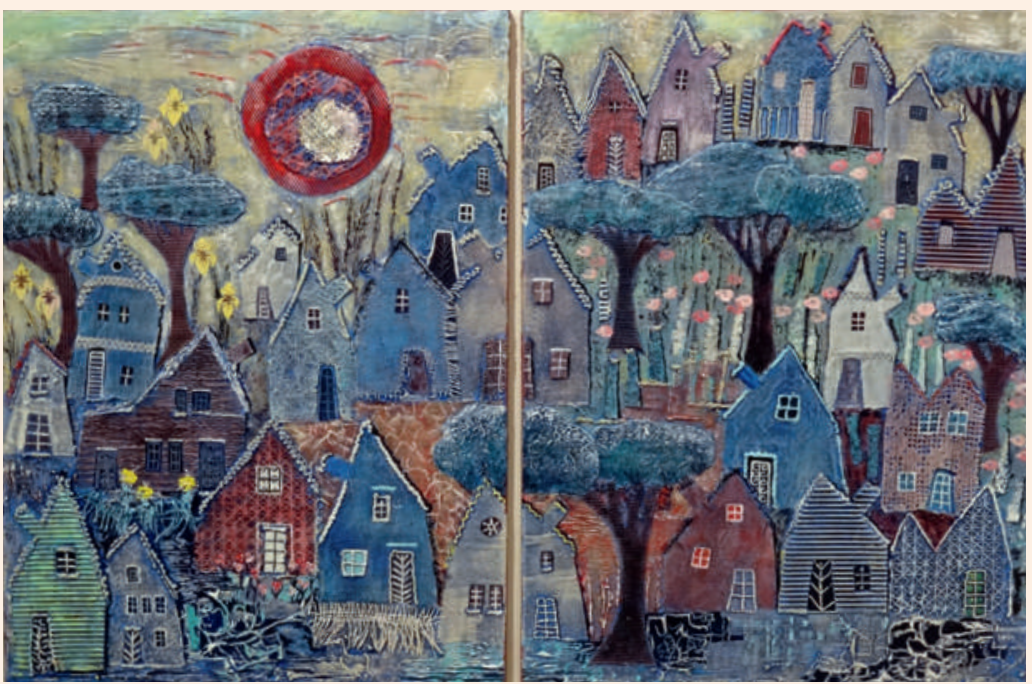

Antoinette Otz-Marbet, «Diptychon Morgenstimmung», Acryl Mischtechnik auf Leinwand, 2014 